\title{
Protagonismo da Clínica de Direitos Humanos e Meio Ambiente da Universidade Federal de Mato Grosso e sua atuação política e multicultural
}

\section{Performance of the Human Rights and Environment Clinic at the Federal University of Mato Grosso and its political and multicultural scope}

\section{Actuación de la Clínica de Derechos Humanos y Medio Ambiente de la Universidad Federal de Mato Grosso y su acción política y multicultural}

Carlos Teodoro José Hugueney Irigaray, doutor em Direito pela Universidade Federal de Santa Catarina, professor associado e coordenador do Programa de Pós-Graduação em Direito Agroambiental da Universidade Federal de Mato Grosso. Endereço: Rua Nossa Senhora da Guia, 242 - Chácara dos Pinheiros. CEP: 78080-070 - Cuiabá, MT. Telefones: (65) 36611264 / 99968998. E-mail: teodoro.irigaray@gmail.com.

\section{Resumo}

Este artigo analisa a concepção e o funcionamento da Clínica de Direitos Humanos e Meio Ambiente da Universidade Federal de Mato Grosso, a partir do contexto em que ela se insere e de seu escopo multicultural, que envolve não apenas a proteção do ambiente natural e sua rica biodiversidade, mas também dos direitos dos povos indígenas e populações tradicionais, revelando tratar-se de um espaço de pesquisa e extensão em que o ativismo de professores comprometidos com a mudança social pode contribuir para a construção de um modelo de desenvolvimento com mais sustentabilidade e justiça social.

Palavras-chave: Clínica de Direito Ambiental. Ativismo Acadêmico. Laboratório de Pós-Graduação. 


\section{Abstract}

This paper analyzes the conception and performance of the Human Rights and Environment Clinic at the Federal University of Mato Grosso (UFMT), from the perspective of the context in which it operates and its multicultural scope, which involves not only the protection of the natural environment and its rich biodiversity, but also the rights of indigenous and traditional populations. It is an area of research and extension in which the activism of professors committed to social change can contribute to building a development model with more sustainability and social justice.

Keywords: Environmental Law Clinic. Academic Activism. Laboratory Graduate.

\section{Resumen}

Este artículo analiza el diseño y el funcionamiento de la Clínica de Derechos Humanos y Medio Ambiente de la Universidad Federal de Mato Grosso, considerando el contexto en que se produce y su alcance multicultural, lo que implica no sólo la protección del medio ambiente y su rica biodiversidad, sino también los derechos de los pueblos indígenas y poblaciones tradicionales, revelando tratarse de un espacio de investigación y extensión en que el activismo de docentes comprometidos con el cambio social puede contribuir a la construcción de un modelo de desarrollo con una mayor sostenibilidad y justicia social.

Palabras clave: Clínica de Derecho Ambiental. Activismo Académico. Laboratorio de Posgrado.

\section{Introdução}

A universidade não pode ser uma ilha fechada em um hermetismo egocêntrico. Deve ser um polo de irradiação do saber, em que professores e alunos se empenham para reverter em ações que 
beneficiem a população os investimentos que a sociedade faz para apoiar as pesquisas, a capacitação e a extensão e assegurar um ensino de qualidade.

Resulta dessa troca uma responsabilidade social que demanda de professores ativismo acadêmico e postura de humildade, afinal, como ponderou Guimarães Rosa, em sua obra-prima, Grande Sertão Veredas: "mestre é aquele que, de repente, aprende" (1993, p. 147).

Além disso, a experiência mostra que iniciativas alicerçadas no idealismo e no comprometimento da cidadania suplantam as limitações materiais; ou, dito de outra forma, com pouco se pode fazer muito. Mostra também que a grande força das universidades está na sua inserção proativa na realidade regional e no universo multicultural característico de nosso País, tarefa em que somos inexperientes e muito temos a aprender.

Nesse sentido, a Universidade Federal de Mato Grosso (UFMT) tem reconhecida dívida para com o estado em que está abrigada e a vem resgatando com investimentos na pesquisa e na pós-graduação relacionadas à questão ambiental, em sua conexão com as diversas áreas do conhecimento.

Afinal, Mato Grosso foi responsável, durante mais de uma década, por cerca de 50\% dos desmatamentos ocorridos na Amazônia e hoje se destaca no cenário nacional como um exportador de commodities, contribuindo com grande parte do superávit primário de nossa balança comercial. Cabe à UFMT revelar a que custo isso tem acontecido, propondo alternativas para reduzir esse passivo ambiental e humanizar esse modelo de exploração predatória.

Este artigo enfoca apenas uma parcela do trabalho desenvolvido pela UFMT: a atuação de sua Faculdade de Direito e do Programa de PósGraduação em Direito Agroambiental, visando abordar especialmente a atuação política e cultural de sua Clínica de Direitos Humanos e Meio Ambiente. 
Pretende-se com este trabalho mais do que disseminar uma experiência mato-grossense que tem sido exitosa; o que se quer é abrila a uma crítica que possa contribuir para o seu aprimoramento.

\section{Contextualização: três biomas em um estado amazônico}

Analisar a atuação socioambiental da Faculdade de Direito da UFMT pressupõe conhecer as especificidades que caracterizam a realidade regional em que ela se insere, bem como as nuanças do padrão de desenvolvimento econômico excludente, ainda hoje empregado nesse processo de "re"colonização da Amazônia.

A Amazônia brasileira permaneceu, até meados do século XX, baseada em um modelo extrativista, com uma ocupação esparsa, localizada na calha dos grandes rios. Nesse padrão fluvial, o rio comandava a vida. A partir da década de 60, com a Marcha para o Oeste, incentivada pela ditadura militar, teve início o modelo agropecuário/ rodoviário - com a subversão dos padrões de colonização até então conhecidos na região. A ausência de políticas passou a ser uma opção política desastrosa. Isso gerou intensos conflitos sociais e impactos ambientais negativos e nos deixou a lição de como não planejar uma região. As declarações de Delfim Netto, então Ministro de Planejamento (1978), citadas por Schmink e Wood (2012), ilustram o processo que se instaurou e ainda perdura na região: "Primeiro, faremos um velho oeste na Amazônia. E, aí, chamamos o xerife."

Esse velho oeste se manifesta na ausência do Estado, na grilagem de terras públicas, nos desmatamentos e queimadas ilegais, feitas quase sempre com trabalho escravo, e na violência no campo, onde os índices de assassinatos superam as mais violentas capitais do Brasil, o que demonstra que o "xerife" ainda não chegou e prova a ausência do Estado nos rincões mais violentos da fronteira agropecuária.

O fato é que, da área de floresta existente no território brasileiro, cerca de $20 \%$ já foi desmatado, ou seja, quase 70 milhões de hectares. Apesar das ações governamentais direcionadas para reverter o avanço da fronteira agrícola sobre a floresta, as taxas de desmatamento se 
mantêm elevadas e, embora se constate uma gradativa redução desse percentual', ele pode estar associado à conjuntura do mercado. Não há nenhuma segurança de que o desmatamento será contido com o aquecimento da economia, mesmo porque, paradoxalmente, verifica-se um aumento de investimentos do Governo Federal em grandes obras na Amazônia, tendo como contrapartida a redução dos investimentos em conservação ambiental.

Ao examinar a contribuição dos estados amazônicos para a sangria da floresta, cabe destacar a posição mato-grossense: depois de liderar durante muitos anos o ranking dos estados em desmatamento e queimadas, agora ocupa a primeira posição entre os que mais consomem agrotóxicos.

A despeito das altas taxas de desmatamento, Mato Grosso ocupa também uma posição relevante, não apenas por sua diversidade socioambiental, mas também pela sua importância econômica e por sua rica biodiversidade. Cabe assinalar que o estado abriga três biomas distintos: a Floresta Amazônica (53,6\%), o Cerrado (39,6\%) e o Pantanal Mato-Grossense $(6,8 \%)$, cada um deles com suas peculiaridades e seus problemas similares associados ao modelo de desenvolvimento econômico dominante.

Os números acima citados ilustram a dimensão desses biomas, incluindo o menor deles (o Pantanal Mato-Grossense), que constitui a maior área úmida do planeta; o Cerrado, como a savana dotada de mais rica biodiversidade e que funciona como berço das águas, uma vez que os principais rios do País nascem nesse bioma; e a Floresta Amazônica, que ocupa cerca de $50 \%$ do território estadual.

No plano da sociodiversidade, vivem em Mato Grosso indígenas e quilombolas, além do fluxo de migrantes sulistas que para lá foram atraídos pela política de ocupação da Amazônia, como se a região fosse um grande "vazio" que deveria ser subjugado, conforme pontuam Faria et al.

O mito do "vazio" constrói duas importantes ideias-força, a negação dos povos autóctones e a necessidade de colonização pela população
1 Segundo dados do Inpe, em 2012 a taxa de desmatamento foi de 4.656 quilômetros quadrados, o que corresponde a cerca de 32 hectares de floresta desmatados por hora (Fonte: Prodes/Inpe-EM). 
exógena. Trabalho e terra cativos geram um binômio de exploração capaz de engendrar uma sociedade excludente e sem aspirações de desenvolvimento social. Estas características, em maior ou menor grau, reverberaram pelos séculos e se conformaram na economia matogrossense (no prelo).

Essas políticas tiveram efeitos desastrosos, especialmente sobre as populações indígenas, e levaram à dizimação de algumas nações, entre as quais os ferozes Paiaguás nominados no Hino de Mato Grosso².

No que se refere ao aspecto econômico, houve um crescimento médio de 7,36\% por ano (entre 2002/2009), percentual bem acima da média nacional no mesmo período (5,65\%), quando a agropecuária respondeu por 30\% do PIB. 0 estado tem hoje o maior rebanho bovino do País, além de ocupar a primeira posição na produção de soja e algodão, embora os aspectos ambientais e sociais não tenham sido contemplados no processo de desenvolvimento. Verifica-se que Mato Grosso tem uma economia fortemente dependente dos ciclos naturais (chuva, solo, fluxo de energia solar, polinização, pragas etc.) e, portanto, sensivel às mudanças climáticas alimentadas pelo desmatamento e pelas queimadas, práticas com as quais o estado segue contribuindo significativamente.

Cabe salientar que a expansão do agronegócio, que tem sido festejada pelo superávit primário que gera em benefício da economia nacional, ocorre alimentada por subsídios explícitos e implícitos vultosos concedidos pelo estado. Nos incentivos explícitos deve ser contabilizada a renúncia fiscal, que, só em 2009, foi estimada em cerca de $\mathrm{R} \$ 1,52$ bilhão, e superando os orçamentos da educação e também da saúde no estado. Segundo dados apurados no Relatório de Auditoria dos Incentivos Fiscais concedidos pelo governo do estado de Mato Grosso (TCE-MT, 2009, p. 44),

${ }^{2}$ A segunda estrofe do Hino de Mato Grosso enaltece os primeiros colonos que dizimaram algumas nações indigenas: "Eis a terra das minas faiscantes, Eldorado como outros não há, que o valor de imortais bandeirantes, conquistou ao feroz Paiaguá!” produzido pelo Tribunal de Contas do Estado, a renúncia fiscal apurada em 2008 somou R\$1,2 bilhão, enquanto o orçamento da educação, no mesmo ano, ficou em $R \$ 918$ milhões, e o da saúde com $R \$ 714$ milhões. Em 2009, a renúncia fiscal correspondeu a cerca de 83\% dos orçamentos da educação e saúde somados.

Já os subsídios implícitos referem-se aos prejuízos ambientais tolerados pelo estado em uma conhecida equação na qual os lucros 
são privatizados e os prejuízos socializados. Cita-se, como exemplo, a contaminação do solo e dos recursos hídricos por agrotóxicos, ou mesmo o desmatamento ilegal e a grilagem de terras públicas, práticas toleradas pelo Poder Público, que não consegue arrecadar mais do que $2 \%$ das multas aplicadas por violações à legislação ambiental.

Outro fato que não pode ser ignorado é o de que nos estados da Amazônia, nas últimas décadas, o poder político foi ocupado por uma elite agrária pouco comprometida com a gestão ambiental e com os direitos das populações indígenas. Em recente estudo conduzido pelo jornalista Castilho (2012), foram analisadas quase 13 mil declarações de políticos eleitos em 2008 e 2010, demostrando que políticos de todas as regiões do País possuem terras na Amazônia e no Cerrado, forjando um "sistema político ruralista”.

Segundo o autor, além de senadores e deputados federais e estaduais que integram essa elite ruralista, no estado de Mato Grosso, $62,41 \%$ dos prefeitos $(78,72 \%$, se incluídos os vice-prefeitos) são também proprietários rurais.

Como consequência, a ocupação da Comissão do Meio Ambiente da Câmara pela chamada bancada ruralista conta com o aval de um Congresso que, à semelhança da República Velha, é formado por grandes proprietários mais preocupados com os próprios interesses do que com os interesses de um País megadiverso e plurinacional.

Esse quadro explica os retrocessos na proteção do meio ambiente que ocorrem não apenas no plano legal (vide: Código Florestal, Lei Complementar n 140/2011), mas também na ostensiva atuação de agentes públicos comprometidos com uma política desenvolvimentista (vide, por exemplo, os licenciamentos de grandes obras ou a Portaria n 303/2012 da Advocacia-Geral da União - AGU, para a qual o direito dos povos indígenas nada mais é que um entrave que deve ser desconsiderado).

Nesse contexto, que contribuição uma instituição pública de ensino superior da "periferia" (na perspectiva colonialista reproduzida 
pelas agências de gestão do conhecimento) pode dar à concretização de um direito ambiental em que esteja também assegurado o direito à diversidade cultural e o direito das populações indígenas e quilombolas? É trivial dizer que "o caminho se faz caminhando". Sem muitas referências compativeis com a realidade regional, foram dados os primeiros passos para a construção do pequeno escritório que foi o embrião da clínica atualmente existente na UFMT.

\section{Os primeiros passos}

Pensou-se inicialmente que a Faculdade de Direito da UFMT poderia contribuir para a contenção do desmatamento prestando apoio ao Ministério Público estadual na propositura de ações civis públicas de responsabilização por desmatamentos ilegais na Amazônia matogrossense. Mas, afinal, esse apoio era necessário? Empiricamente, não havia dúvidas, mas uma pesquisa de campo poderia comprovar tal necessidade. Com essa finalidade, um projeto de pesquisa conduzido no âmbito da FD-UFMT, em 2006, sob coordenação do autor, constatou o que se sabia informalmente: em Mato Grosso, a impunidade era a regra.

O Ministério Público não possuía sequer informações sobre as ações propostas contra desmatamentos ilegais no interior do estado, e o Judiciário não tinha condições de informar o número de ações civis públicas propostas; por isso, optou-se por enviar ao interior do estado alunos da graduação, que levantaram in loco o número de ações civis e criminais propostas contra desmatamentos ilegais. Na oportunidade, foram pesquisados os municípios que lideraram o desmatamento ilegal, e os dados obtidos foram surpreendentes: nos municípios que mais desmataram, nenhuma ação civil pública havia sido proposta contra os responsáveis visando à reparação de danos. Apenas cinco ações criminais foram encontradas, e todas relativas a pequenos

${ }^{3}$ A Fundação Estadual do Meio Ambiente era, à época, o órgão estadual do meio ambiente; foi substituída posteriormente pela Secretaria de Estado do Meio Ambiente (Sema) desmatamentos.

Paralelamente, outros bolsistas fizeram um levantamento das autuações nos casos de desmatamentos ilegais implementadas pela Fema ${ }^{3}$ e pelo órgão federal do meio ambiente, o Instituto Brasileiro do Meio 
Ambiente e dos Recursos Naturais Renováveis (Ibama), classificandoos segundo a dimensão da área desmatada. Como resultado dessa investigação, constatou-se que os 40 maiores desmatamentos autuados pelo órgão estadual do meio ambiente envolviam áreas acima de 2.000 hectares e nenhuma medida judicial havia sido tomada contra esses infratores. Uma conclusão inafastável foi a de que os grandes degradadores continuavam impunes e que as poucas ações propostas se voltavam contra os menores desmatamentos, ou seja, não havia uma estratégia eficiente para otimizar os poucos recursos dos órgãos ambientais e do MP.

Mister assinalar que a Promotoria de Justiça nas cidades do interior da Amazônia (onde estão concentrados os maiores desmatamentos) é também responsável pelas ações criminais e pelos procedimentos nas áreas da Infância e Juventude, Eleitoral e de Família, entre outras, e não conta com uma estrutura mínima para desempenhar suas atribuições. Portanto, não é razoável exigir melhor desempenho na área ambiental, sem que sejam oferecidas as condições mínimas para tanto.

Delineou-se, nesse cenário, que uma contribuição importante que a Faculdade de Direito poderia dar no enfrentamento do problema identificado seria a criação de um Escritório Modelo de Advocacia Ambiental (Emaa) que pudesse apoiar a atuação dos órgãos públicos na responsabilização por danos decorrentes de desmatamentos ilegais. Essa ideia se efetivou, por iniciativa do autor, com a criação do Emaa, a definição de uma linha de atuação e a busca de parcerias que pudessem apoiar tal projeto.

A Universidade da Flórida e o Instituto Centro de Vida apoiaram o Emaa, possibilitando a contratação da advogada Gisele Ferreira Vieira, que foi credenciada como professora voluntária na UFMT e passou a exercer a gerência-executiva do referido escritório, bem como o pagamento de bolsa a dois estagiários que apoiaram os trabalhos do Emaa na fase inicial.

Uma das primeiras ações desenvolvidas pelo Emaa foi a elaboração de uma minuta de ação civil pública por danos decorrentes 
de desmatamentos ilegais. Essa minuta foi encaminhada aos promotores de justiça das comarcas do interior, acompanhada de dossiês denominados Relatório de Dano Individualizado (Rida). Nele, além de cópia da autuação lavrada pela Fema, constava mapa georreferenciado com a identificação da área desmatada e a descrição dos danos causados em Áreas de Preservação Permanente e Reserva Legal e dados que permitiam a identificação do infrator. Foram priorizados nessa tarefa os 150 maiores desmatamentos ocorridos no ano.

Desse modo, o promotor de Justiça da comarca onde se efetivou o dano recebia uma minuta de ação civil pública, em meios impresso e digital, devidamente instruída e pronta para ser ajuizada, o que permitiu, durante o primeiro ano, a propositura de mais de 100 ações civis públicas relativas aos maiores desmatamentos ocorridos em Mato Grosso.

Os custos dessa iniciativa foram mínimos se considerados os resultados alcançados. Não se contabiliza como resultado a recuperação dos danos ou o pagamento de uma indenização que, eventualmente, poderá acontecer ao longo dos anos, tendo em vista a morosidade do Judiciário brasileiro. O maior resultado foi, seguramente, uma mudança do quadro de impunidade absoluta para uma responsabilização seletiva, priorizando os maiores degradadores, com inegável efeito pedagógico.

Além dessas ações, o Emaa ofereceu contribuições ao governo do estado de Mato Grosso na definição de medidas visando reduzir os índices de desmatamento. Partiu do Emaa a proposta de institucionalização de um Cadastro Ambiental Rural, similar ao implantado pelo estado do Pará, objetivando inserir em uma base de dados pública, a ser gerida pela Sema-MT, as propriedades rurais cadastradas, com uma declaração do respectivo passivo e a identificação do proprietário ou possuidor, como será enfatizado neste trabalho.

Importante registrar que esse Escritório Modelo de Advocacia Ambiental foi o embrião das clínicas de Direito Ambiental criadas no Brasil. Nesse processo, deve ser destacado o apoio da Universidade da Flórida - UFL, onde funciona uma atuante Clínica de Direito Ambiental (vinculada ao Levin College of Law), que permitiu a participação da Profa. 

multicultural

Giselle Vieira e de alunos da graduação da UFMT em cursos promovidos pela UFL na Universidade da Costa Rica, onde também existe uma clínica similar. Como fruto dessa experiência, foi publicado um artigo (IRIGARAY; VIEIRA; FAVA, 2007), em que se apresentou a experiência do Escritório Modelo de Advocacia Ambiental da UFMT, juntamente com um projeto de organização e funcionamento de escritórios similares a serem implementados e adequados à realidade da região amazônica e suas universidades, bem como das demais universidades da América Latina, ampliando o alcance da especialização ambiental e da inserção social da academia no enfrentamento das questões ambientais.

Nessa sua fase inicial, o Emaa esteve vinculado ao Núcleo de Estudos e Prática Jurídica Ambiental - Nepa, sob a coordenação do Prof. Luiz Alberto Scaloppe, que agregou às ações de prática jurídica a oferta de cursos de especialização em Direito Ambiental, Direito Urbanístico e Direito Agroambiental, os dois primeiros oferecidos na modalidade a distância e o último (já em sua quarta edição) oferecido na modalidade presencial.

Estavam dados assim os primeiros passos para a transformação do Emaa em uma clínica de Direito Ambiental, o que se efetivou inicialmente com o nome de Clínica de Direito Agroambiental, tendo em vista a superveniente criação do Programa de Pós-Graduação em Direito Agroambiental. Mais recentemente, foi nomeada Clínica de Direitos Humanos e Meio Ambiente, mesmo porque a atuação política da clínica se efetiva preponderantemente, mas não exclusivamente, na área da política ambiental, interessando aos pesquisadores que nela atuem também a conexão dessas políticas com os direitos indígenas e das populações tradicionais, bem como a proteção dos recursos necessários à sua reprodução cultural.

Embora a expressão clínica de Direito tenha sido criticada em uma "resistência anticolonialista", uma vez que é uma expressão adotada, sobretudo, nos Estados Unidos, prevaleceu a opção por essa denominação, que já se consolidou não apenas nos EUA, mas também em países da Europa e mesmo na América Latina, onde se destaca a Clínica de Direito Ambiental da Costa Rica, além do fato de que clínica tem uma concepção mais ampla do que escritório modelo. 
No item seguinte, a atuação política e multicultural da Clínica de Direitos Humanos e Meio Ambiente da UFMT será enfocada visando identificar os desafios e as oportunidades gerados por essa iniciativa.

\section{A Clínica de Direitos Humanos e Meio Ambiente da UFMT}

Pensar uma clínica que trabalhe com direitos humanos e proteção ambiental não é tarefa que possa se dissociar do ambiente jurídico político, em que há espaço para movimentos emancipatórios e para a construção de uma nova concepção de ordem estatal, característica de um Estado de Direito Socioambiental.

Cumpre ressaltar que Canotilho e Leite destacam a cidadania participativa como característica desse novo modelo de Estado:

A consecução do Estado de Direito Ambiental passa obrigatoriamente pela tomada de consciência global da crise ambiental e exige uma cidadania participativa, o que compreende uma ação conjunta do Estado e da coletividade na proteção ambiental. Trata-se definitivamente, de uma responsabilidade solidária e participativa, unindo de forma indissociável Estado e cidadãos na preservação do meio ambiente (2007, p.153-154).

É certo que tal tarefa ganha novo impulso se a própria ordem constitucional fortalece os movimentos emancipatórios e a participação pública. Pertinente a observação de Marés e Arbos relativamente às constituições que surgiram a partir da década de 80:

As novas constituições foram surgindo com um forte caráter pluricultural, pluriétnico e preservador da biodiversidade. Ao lado do individualismo homogeneizador, reconheceu-se um pluralismo repleto de diversidade social, cultural e natural, numa perspectiva que se pode chamar de socioambiental.

Os sistemas jurídicos constitucionais, antes fechados ao reconhecimento da pluriculturalidade e da multietnicidade, foram reconhecendo, um a um, que os países do continente têm uma variada formação étnica e cultural, e que cada grupo humano que esteja organizado segundo sua cultura e viva segundo sua tradição, em conformidade com a natureza da qual participa, tem direito à opção de seu próprio desenvolvimento (2010, p. 25-39). 
O fato é que a Constituição brasileira dedica importantes dispositivos à proteção dos recursos naturais e do meio ambiente, bem como das minorias étnicas, conforme abordado por Santilli:

A concepção abrangente adotada pela Constituição foi a de que não é possivel compreender os bens culturais sem considerar os valores neles investidos e o que representam - a sua dimensão imaterial - e, da mesma forma, não se pode entender a dinâmica do patrimônio imaterial sem o conhecimento da cultura material que lhe dá suporte. Procurou, assim, abranger as manifestações esculturais de caráter processual e dinâmico, em geral, transmitidas oralmente. [...]

O capítulo dedicado aos povos indígenas assegura proteção não só às terras tradicionais indígenas e aos recursos naturais nelas existentes - bens materiais ou tangíveis -, como também aos seus costumes, línguas, crenças e tradições - bens imateriais ou intangíveis, de natureza processual e dinâmica (2005, p. 78).

O reconhecimento de direitos coletivos (econômicos, sociais, culturais e ambientais) dos povos indígenas e quilombolas e da necessidade de proteção de bens comuns, indispensáveis à reprodução cultural dos diferentes grupos étnicos e sociais que integram a sociedade brasileira, também orientou a atuação da Faculdade de Direito da UFMT na estruturação de sua Clínica de Direitos Humanos e Meio Ambiente e na implantação do sistema de cotas, permitindo o ingresso dos primeiros graduandos indígenas.

Essa clínica, nos termos da resolução proposta pelo autor e aprovada pela Congregação da Faculdade de Direito da UFMT ${ }^{4}$, passa a ter a estrutura de um núcleo vinculado à Faculdade de Direito, sob a administração de um coordenador-geral e um coordenador-adjunto, com os seguintes objetivos:

a) Contribuir para o desenvolvimento de ações de ensino, pesquisa e extensão, fomentando a integração das atividades da Graduação e Pós-Graduação em Direito na UFMT na área dos Direitos Humanos e Agroambiental; e

b) Integrar as ações de pesquisa e extensão do Programa de Mestrado em Direito Agroambiental da UFMT com os demais programas de pós-graduação das universidades amazônicas.
${ }^{4}$ A Resolução aprovada pela Congregação da Faculdade de Direito, em março de 2013, deve ser ratificada pelo Conselho Universitário, órgão da UFMT com competência institucional para a criação de núcleos. 
Para tanto, foram atribuídas à clínica as seguintes competências:

a) Aprofundar o estudo e a discussão pública das questões agroambientais que envolvam direitos humanos e, especialmente, direitos indígenas, apoiando as populações vulneráveis na defesa de seus direitos;

b) Contribuir como Poder Público na formulação e implementação de políticas públicas, por meio de uma incubadora de políticas públicas da Amazônia mato-grossense;

c) Organizar cursos, eventos, congressos, encontros e outras atividades de extensão, visando debater e difundir a produção científica do Programa de Pós-Graduação em Direito Agroambiental;

d) Coordenar a publicação da Revista Amazônia Legal de Estudos Sócio-Jurídico-Ambientais, podendo fazê-lo em parceria com outras IES;

e) Prestar consultorias e executar projetos nas áreas de Direitos Humanos e Agroambiental, no interesse de instituições públicas e privadas; e

f) Firmar convênios e contratos com instituições públicas e privadas, visando à consecução de seus objetivos.

Como assinalado, desde sua concepção, essa foi uma iniciativa relacionada à responsabilidade social das universidades e, portanto, uma ação inerente ao exercício de cidadania ecológica, cuja existência implica um ativismo ecológico, característico do Programa de Pós-Graduação em Direito Agroambiental da UFMT.

Nesse sentido, a clínica foi constituída como Laboratório do Programa de Pós-Graduação em Direito Agroambiental da UFMT ${ }^{5}$ e funciona como um observatório de acompanhamento das políticas públicas e de ações judiciais que envolvam temas de grande repercussão, além de também funcionar como uma incubadora de políticas públicas voltadas sobretudo para a Amazônia mato-grossense.

Trata-se de concepção que reconhece uma função multissetorial para esse espaço acadêmico, que, por isso mesmo, deve ter uma atuação interdisciplinar, funcionando como uma clínica jurídica que atende 
a demandas de setores da sociedade civil interessados em apoio e esclarecimentos jurídicos na área ambiental. Nesse sentido, a clínica ofereceu seus serviços, por exemplo, para apoiar a comunidade indígena do Meruri, na discussão do licenciamento ambiental de hidrelétricas previstas para o Rio Garças que afetarão direta e indiretamente os índios bororos.

Na sua atuação como laboratório, algumas pesquisas estão sendo desenvolvidas, como as que integram o Programa de PósGraduação em Direito Agroambiental da UFMT (PPGDA) no Fórum de Pesquisa e de Pós-Graduação em Desenvolvimento Sustentável da Amazônia, ou, ainda, o funcionamento do Grupo de Pesquisa Jus-Clima, além do envolvimento em pesquisas que reúnem outras instituições de ensino superior, como o Projeto de Pesquisa Perspectivas e desafios para a proteção da Biodiversidade no Brasil e na Costa Rica, que congrega a UFSC, a USP, a UFMT e a Universidade da Costa Rica. Ainda como laboratório, registram-se as orientações a estudantes indígenas (Pibic-Ação Afirmativa), conduzidas pelo autor, visando à discussão do impacto de hidrelétricas em terras indígenas (um problema recorrente na Amazônia) e à responsabilidade por danos ambientais causados no entorno de terras indígenas.

Atuando como observatório, a clínica tem acompanhado o desenrolar da ação civil pública na qual se discute a Lei de Zoneamento Socioeconômico-Ecológico do estado de Mato Grosso e seus potenciais impactos na redução de áreas frágeis e especialmente protegidas, colocando-se à disposição de entidades ambientalistas para atuar como amicus curiae nessa ação, oferecendo pareceres e estudos que demonstram as inconstitucionalidades e os vícios da iniciativa do Legislativo.

Além dessas dimensões, cabe registrar que, vinculada à clínica, funciona a Incubadora de Políticas Públicas da Amazônia Mato-Grossense (Ippa-MT), constituída no âmbito de um projeto de pesquisa desenvolvido pelo Fórum de Pesquisa e Pós-Graduação em Desenvolvimento Sustentável da Amazônia, que congrega mais de 20 programas de pós-graduação da Amazônia e redundou na instalação de incubadoras estaduais. 
Em Mato Grosso, o projeto da incubadora é coordenado pelo autor e congrega professores da UFMT e também do Programa de Pós-Graduação em Ciências Ambientais da Unemat, além de alunos da graduação, com uma estrutura e atuação que seguem descritas no item seguinte.

\section{Incubadora de Políticas Públicas da Amazônia mato-grossense}

A Incubadora de Políticas Públicas da Amazônia mato-grossense - IPPA/MT, instalada em 17 de agosto de 2012, integra uma rede de instituições de ensino, pesquisa e extensão e de planejamento, fomento e financiamento do desenvolvimento regional, sem fins lucrativos, vinculada ao Fórum de Pesquisa e Pós-Graduação em Desenvolvimento Sustentável da Amazônia7, e tem como missão contribuir para o aperfeiçoamento do processo de concepção, formulação, acompanhamento e avaliação de políticas públicas de desenvolvimento sustentável para a Amazônia mato-grossense, apoiadas no conhecimento científico, nos saberes tradicionais e na participação qualificada dos atores regionais. São objetivos específicos da Ippa-MT:

I. Promover a integração entre a academia, os institutos de pesquisa, os órgãos públicos de planejamento, fomento e gestão do desenvolvimento regional, os setores produtivos e a sociedade civil, por intermédio da realização de pesquisas, estudos comparativos e produção de indicadores de desenvolvimento socioambiental, visando apoiar e subsidiar o processo de planejamento regional na Amazônia mato-grossense;

II) Ofertar serviços especializados de assessoria e capacitação de gestores públicos na elaboração e gestão de planos e projetos públicos de desenvolvimento, tanto para as prefeituras dos municípios amazônicos, quanto para outras instituições públicas, governamentais ou não governamentais, da região;

${ }^{6}$ http://www.amazonia ufpa.br/ippa/regional/7. 7 http://www.amazonia. ufpa.br. 
IV) Incentivar e promover o debate em torno dos temas referentes ao desenvolvimento sustentável local e regional em suas dimensões socioeconômica, político-institucional, cultural e ambiental.

A Ippa-MT tem como instância deliberativa um Comitê Gestor, ao qual compete analisar as proposições de políticas públicas voltadas para a consecução do desenvolvimento sustentável na Amazônia matogrossense e deliberar sobre elas. Além dos pesquisadores da UFMT e da Unemat, que atuam na Secretaria-Executiva da Ippa-MT, seu comitê gestor é composto por representantes de diversos órgãos e instituições, que incluem a Secretaria de Estado do Meio Ambiente; a Secretaria de Estado de Planejamento e Coordenação Geral; o Ministério Público estadual; a Superintendência da Fundação Nacional do Índio (FunaiCuiabá/MT); a Federação da Agricultura e Pecuária do Estado de Mato Grosso; o Fórum Mato-Grossense de Meio Ambiente e Desenvolvimento Formad, entre outros.

Trata-se, portanto, de uma instância colegiada que reúne instituições com interesses muitas vezes conflitantes, mas que atua tendo como suporte os pesquisadores da UFMT e Unemat envolvidos. Em uma de suas primeiras reuniões extraordinárias, o comitê gestor definiu um plano ação prioritária da Ippa/MT, visando solucionar/ minimizar os principais problemas de gestão das políticas públicas e tornar mais eficiente e efetiva a gestão e a governança das políticas públicas no estado. Foram definidas as seguintes ordens de prioridades que serão trabalhadas no âmbito da Incubadora:

1) Programa de regularização ambiental;

2) Conservação, gestão e regularização de áreas protegidas;

3) Uso e gerenciamento de recursos hídricos;

4) Contenção de desmatamentos e queimadas;

5) Povos indígenas em Mato Grosso; e

6) Política estadual de educação ambiental.

Para a consecução de seus objetivos, o comitê gestor da Ippa-MT se reúne ordinariamente uma vez por mês. Desde sua criação, a Ippa 
já ofereceu sua contribuição na elaboração da minuta do projeto de lei que regulamenta o Programa Estadual de Regularização Ambiental e deu início a uma discussão sobre o Sistema Estadual de Unidades de Conservação e sobre a Política Estadual de Educação Ambiental. Os pesquisadores envolvidos nessa tarefa estão elaborando minutas de projeto de lei que consolidam as discussões já feitas em diversos fóruns visando à estruturação de uma política para cada uma dessas áreas.

Além dessas ações, os pesquisadores realizaram um diagnóstico sobre as políticas públicas implementadas em Mato Grosso, que redundarão na publicação de três coletâneas, que incluirão a discussão dessa mesma temática nos demais estados amazônicos. Os temas abordados nessa pesquisa são:

1) Instituições, unidades de conservação e desmatamento na Amazônia;

2) Expansão da fronteira, desenvolvimento regional e qualidade de vida na Amazônia; e

3) Gestão colaborativa de recursos naturais e prevenção do desmatamento na Amazônia.

No segundo ano do projeto está prevista uma dinamização das ações da Ippa, por meio de pesquisação nas mesorregiões mais ameaçadas pelo desmatamento. Essa pesquisa será realizada conjuntamente pelos integrantes dos Núcleos de Pesquisa da Ippa e pelos representantes das organizações sociais, econômicas e políticas das mesorregiões mais ameaçadas em cada estado amazônico, incluindo as seguintes tarefas: a) caracterização do sistema ecológico, econômico e social da mesorregião; b) avaliação da dinâmica socioeconômica e das experiências recentes de gestão e manejo de recursos naturais do sistema, por intermédio da análise da gestão de empreendimentos coletivos implantados em áreas de conservação, projetos de assentamento/colonização, comunidades quilombolas e outras populações tradicionais; e c) proposições de estratégias de ação da Ippa para subsidiar a elaboração de políticas públicas e projetos prioritários 

multicultural

para melhorar a governança e a gestão socioambiental das unidades de conservação, dos projetos de colonização e de assentamento localizados na mesorregião estudada.

Em Mato Grosso, essa nova etapa do projeto está sendo desenvolvida na mesorregião norte do estado, identificada, após aplicação dos índices desenvolvidos pela Ippa, como a mais frágil. Ela é composta por 55 municípios, distribuídos em oito microrregiões, sendo que o município mais frágil dessa mesorregião é o de Colniza, localizado na microrregião de Aripuanã. Considerando tratar-se de um polo com presença de IES pública, optou-se pela instalação de uma incubadora no município de Alta Floresta.

\section{Pesquisação: atuação e resultados}

Do ponto de vista metodológico, a experiência da clínica se aproxima da pesquisação, que surgiu da necessidade de superar a lacuna entre teoria e prática, partindo da ideia de que o cientista social deveria sair de seu isolamento, assumindo as consequências dos resultados de suas pesquisas e colocá-los em prática, para interferir no curso dos acontecimentos, conforme observa Engel:

\footnotetext{
A pesquisação é um tipo de pesquisa participante engajada, em oposição à pesquisa tradicional, que é considerada como "independente", "nãoreativa" e "objetiva". Como o próprio nome já diz, a pesquisação procura unir a pesquisa à ação ou prática, isto é, desenvolver o conhecimento e a compreensão como parte da prática. É, portanto, uma maneira de se fazer pesquisa em situações em que também se é uma pessoa da prática e se deseja melhorar a compreensão desta (2000, p. 182).
}

Segundo o autor, a pesquisação parte de um modo de encarar a natureza da pesquisa que foge ao tradicional, ou seja, parte do pressuposto de que não existem verdades científicas absolutas, pois todo conhecimento científico é provisório e dependente do contexto histórico em que os fenômenos são observados e interpretados. Além disso, os próprios padrões de pesquisa estão sujeitos à mudança à luz da prática, não havendo, portanto, uma metodologia científica universal e histórica (ENGEL, 2000). 
Nesse sentido, a atuação da clínica e, especialmente, da incubadora a ela vinculada envolve uma pesquisação na medida em que os professores que dela participam se inserem no contexto social, visando contribuir na formulação e implementação de políticas públicas de desenvolvimento e meio ambiente, sobretudo aquelas voltadas para assegurar maior efetividade às leis ambientais e à proteção da biodiversidade.

Da mesma forma, as pesquisas ligadas ao Grupo de Pesquisa em Direito e Mudanças Climáticas incluem, por exemplo, ações concretas desenvolvidas no âmbito da clínica, como a participação em reuniões do grupo de trabalho constituído no âmbito do Fórum Mato-Grossense de Mudanças Climáticas, incumbido de elaborar a proposta de uma política de Redução de Emissões por Desmatamento e Degradação (REDD), partindo do pressuposto de que a necessária contenção do desmatamento na Amazônia mato-grossense exige uma abordagem que combine o uso de instrumentos de comando e controle com instrumentos econômicos, e que a REDD tenha o potencial de contribuir, com baixo custo, para reduzir as emissões de carbono decorrentes do desmatamento.

Entre as ações já desenvolvidas pela Clínica de Direitos Humanos e Meio Ambiente, insere-se a oferta de cursos de capacitação de representantes de ONGs em órgãos ambientais, visando assegurar uma participação pública mais consistente nos órgãos ambientais colegiados, ou, ainda, curso para membros de Conselhos Municipais de Meio Ambiente, tendo sido ofertado, em 2012, um curso aos membros do Condema de Alta Floresta, cidade onde a Ippa-MT instalou uma incubadora regional.

A clínica também ofereceu contribuição na estruturação de um programa pioneiro de regularização do passivo ambiental em MT, que, em linhas gerais, inspirou o Programa de Regularização Ambiental previsto no novo Código Florestal. Partiu da clínica da UFMT, em uma ação coordenada pelo autor, a proposta de vinculação do Programa de Regularização Ambiental ao cadastramento das propriedades rurais, em um sistema nominado de Cadastro Ambiental Rural - CAR, visando possibilitar a identificação dos proprietários com o sensoriamento 
remoto de suas áreas e, assim, melhorar o sistema de controle do órgão ambiental e da sociedade civil. A ideia, submetida a uma comissão governamental criada no âmbito da PGE-MT, foi acolhida e convertida na Lei Complementar estadual n²43/2008 e, agora, mais recentemente, inserida no Código Florestal em vigor.

No que se refere às ações de capacitação, a clínica tem investido na capacitação de promotores de Justiça da Amazônia, por considerar a atuação do parquet essencial à contenção do desmatamento na região, não apenas pela titularidade da ação civil pública visando à responsabilização por danos, mas também por sua atuação preventiva, de inegável alcance e importância. Nesse sentido, promoveu, com apoio do Environmental Law Institute (ELI-USA) e do Ministério Público estadual do Mato Grosso e do Pará, dois importantes eventos voltados para a atualização de promotores que atuam na área ambiental.

Também tem partido da clínica mato-grossense o esforço para a estruturação de uma rede de clínicas de Direito Ambiental da Amazônia, tendo sido realizados em Cuiabá três Encontros Nacionais de Prática Jurídica Ambiental.

Como perspectiva de sua atuação, a Clínica de Direitos Humanos e Meio Ambiente pretende apoiar o Centro de Pesquisa do Pantanal na discussão pública e formulação de uma minuta de lei federal visando à gestão e proteção do Pantanal Mato-Grossense.

Também se insere em suas metas a estruturação de uma força-tarefa objetivando apoiar os povos indígenas na defesa de seus direitos vulnerados por grandes obras na Amazônia, especialmente as hidrelétricas.

\section{Considerações finais}

A solução de um problema não deve ser buscada nas mesmas bases ideológicas em que ele foi forjado. Em um Estado onde impera, desde sua colonização, uma visão exógena com a negação do olhar dos nativos e de suas formas de reprodução social e onde a apropriação 
do espaço político pelos novos colonos impõe um modelo importado de exploração predatória, o enfrentamento dessas questões tem, necessariamente, que se dar pela via da participação pública e do ativismo acadêmico que reconheça como responsabilidade social da universidade contribuir para essa mudança.

A inserção da universidade nesse processo deve ser considerada desde uma perspectiva poliangular. De um lado, com tal ação, a academia retribui à sociedade os investimentos aplicados no financiamento do ensino e da pesquisa, e isso se aplica também às universidades privadas, uma vez que competem com as IES públicas pelos escassos recursos disponibilizados pelo Estado para a educação.

Em outra perspectiva, o ensino do Direito supera os esquemas dogmáticos ainda persistentes e se volta à prática jurídica como instrumento de educação para a cidadania, o que é especialmente relevante nessa área do Direito, que tem uma dimensão revolucionária e propugna uma mudança de paradigma civilizatório. Nesse contexto, a omissão política da academia é ideológica, ou seja, é uma posição política que agrava a alienação dos acadêmicos, formando meros "operadores do Direito" comprometidos exclusivamente com projetos pessoais.

Sem ignorar a contribuição dos grandes centros à produção jurídica, deve ser reconhecido o esforço redobrado de abnegados professores que lutam para manter um programa de pós-graduação em uma IES pública da periferia e se dedicam à pesquisação, visando contribuir na formulação e implementação de políticas públicas que se prestem, efetivamente, a construir uma sociedade mais justa e um desenvolvimento mais equitativo e sustentável.

Recebido em: 30/04/2013

Aprovado em: 17/03/2014 


\section{Referências bibliográficas}

CASTILHO, A. L. Partido da Terra - como os políticos conquistam o território brasileiro. São Paulo: Contexto, 2012.

ENGEL, G. I. Pesquisa-ação. Educar, Curitiba, n. 16, 2000.

FARIA, A. M. M. et al. (no prelo). Evolução Socioeconômica de Mato Grosso. Naea-UFPA.

IRIGARAY, C. T. J. H.; VIEIRA, G. F.; FAVA, G. Prática Jurídica Ambiental: A atuação do Escritório Modelo de Advocacia Ambiental da UFMT no combate ao desmatamento ilegal em Mato Grosso. Revista Amazônia Legal de Estudos Socio-Jurídico-Ambientais, v. 3. Cuiabá: EditUFMT, 2007.

LEITE, J. M.; CANOTILHO, J. J. G. (Org.). Direito Constitucional Ambiental Brasileiro. São Paulo: Saraiva, 2007.

MARÉS, C. F.; ARBOS, K. Constitucionalismo X Democracia: O multiculturalismo e as comunidades tradicionais. Revista da Faculdade de Direito da UFG, v.34, n. 1, p. 25-39, jan./jun. 2010.

ROSA, J. G. Grande Sertão: Veredas. 3 ed. Rio de Janeiro: José Olympio, 1993.

SANTILLI, J. Socioambientalismo e novos direitos. São Paulo: Peirópolis, 2005.

SCHMINK, M.; WOOD, C. Conflitos Sociais e a Formação da Amazônia. Nova lorque: Columbia University Press, 2012.

TCE-MT - Tribunal de Contas do Estado de Mato Grosso. Relatório de Auditoria dos Incentivos Fiscais concedidos pelo Governo do Estado de Mato Grosso. Cuiabá: TCE-MT, 2009. 